\title{
Redução da severidade da brusone do trigo com aplicação foliar de sulfato de zinco
}

\author{
Cristiano Moreira@ ${ }^{1}$, Marcos Antônio Camacho@ ${ }^{2}$, Felipe André Sganzerla Graichen@ ${ }^{3}$
}

${ }^{1}$ Universidade Estadual de Mato Grosso do Sul, Programa de Pós-Graduação em Agronomia, Rod. Graziela Maciel Barroso, Km 12, CP 25, CEP 79200-000, Aquidauana, MS, Brasil; ${ }^{2}$ Laboratório de Nutrição de Plantas, Universidade Estadual de Mato Grosso do Sul, Rod. Graziela Maciel Barroso, Km 12, CP 25, CEP 79200-000, Aquidauana, MS, Brasil. ${ }^{3}$ Laboratório de Fitossanidade, Universidade Estadual de Mato Grosso do Sul, Rod. Graziela Maciel Barroso, Km 12, CP 25, CEP 79200-000, Aquidauana, MS, Brasil.

Email: Felipe André Sganzerla Graichen (felipeandre@uems.br.)

Data de chegada: 01/10/2019. Aceito para publicação em: 01/06/2020.

$10.1590 / 0100-5405 / 229435$

\section{RESUMO}

Moreira, C.; Camacho, M.A.; Graichen, F.A.S. Redução da severidade da brusone do trigo com aplicação foliar de sulfato de zinco. Summa Phytopathologica, v.46, n.3, p.255-259, 2020.

A brusone do trigo, causada pelo fungo Magnaporthe oryzae, está entre os fatores que apresenta maior risco na produção de trigo, pois os danos podem ser superiores a $90 \%$ em safras com condições ambientais favoráveis ao desenvolvimento da doença. O objetivo do trabalho foi avaliar o efeito de sulfato de zinco sobre a severidade de M. oryzae em folhas de trigo, a produção de peróxido de hidrogênio e de morte celular da planta. Avaliouse a severidade da doença em função da aplicação foliar de $\mathrm{Zn}(0 ; 0,4 ; 0,8$; 1,2 e 1,6\% de sulfato de zinco) em diferentes cultivares de trigo (Mirante, Safira, Madre Pérola e Ônix). Além disso, com objetivo de verificar qual possível componente histológico está envolvido na redução da severidade da brusone, realizou-se um experimento com aplicação de sulfato de zinco a $0,4 \%$ na $3^{\text {a }}$ folha e sem aplicação (água destilada) na cultivar de trigo
Safira, que é suscetível a essa doença. Três dias após a aplicação de $\mathrm{ZnSO}_{4}$, as plantas foram inoculadas com suspensão de $10^{4}$ conídios. $\mathrm{mL}^{-1}$ de $M$. oryzae e mantidas em câmara úmida durante $24 \mathrm{~h}$, procedendo-se a coleta das folhas às $18 ; 24 ; 30 ; 36 ; 48$ e 72 horas após a inoculação (hai). As folhas foram fragmentadas e clareadas a fim de avaliações histopatológicas, para as respostas de produção de peróxido de hidrogênio e morte celular, durante a infecção de trigo por $M$. oryzae. Houve redução de severidade da brusone quando aplicado zinco em diferentes concentrações nas cultivares, com exceção da cultivar Ônix. O zinco $0,4 \%$ não teve efeito nos eventos de infecção, com exceção de morte celular 48 hai. Cultivar de trigo e concentrações de sulfato de zinco influenciam na eficiência da redução da severidade da doença.

Palavras-chave: Espécies reativas de oxigênio, morte celular, Pyricularia oryzae, Triticum aestivum

\section{ABSTRACT}

Moreira, C.; Camacho, M.A.; Graichen, F.A.S. Reduction in wheat blast severity with foliar application of zinc sulfate. Summa Phytopathologica, v.46, n.3, p.255-259, 2020.

Wheat blast, caused by the fungus Magnaporthe oryzae, is among the factors of highest risk for wheat production because losses can be greater than $90 \%$ in crop seasons with favorable environmental conditions to the development of this disease. The objective of this study was to evaluate the effect of zinc sulfate on M. oryzae infection in wheat leaves, as well as hydrogen peroxide production and cell death in the plant. The disease severity was evaluated as a function of foliar application of $\mathrm{Zn}(0,0.4 \%, 0.8 \%, 1.2 \%$ and $1.6 \%$ zinc sulfate) in four different wheat cultivars ('Mirante', 'Safira', 'Madre Pérola' and 'Ônix'). In addition, with the aim of verifying which histological component is possibly involved in reducing blast severity, an experiment was carried out with application of $0.4 \%$ zinc sulfate onto the $3^{\text {rd }}$ leaf and without application (distilled water) in the cultivar 'Safira', which is susceptible to this disease. Three days after $\mathrm{ZnSO}_{4}$ application, the plants were inoculated with $10^{4}$ conidia. $\mathrm{mL}^{-1}$ suspension of $M$. oryzae and kept in a humid chamber during $24 \mathrm{~h}$; leaves were collected at 18, 24, 30, 36, 48 and 72 hours after inoculation (hai). The leaves were fragmented and bleached for histopathological evaluations of the responses of hydrogen peroxide production and cell death during wheat infection by $M$. oryzae. Wheat blast severity reduced when zinc was applied at different concentrations in all cultivars, except 'Onyx'. Zinc at $0.4 \%$ had no effect on infection events, except for cell death at 48 hai. The wheat cultivar and the zinc sulfate concentrations influenced the disease severity reduction efficiency.

Keywords: Reactive oxygen species, cell death, Pyricularia oryzae, Triticum aestivum

O trigo é um dos cereais mais produzidos no mundo. Inicialmente produzido no sul do Brasil, e com os avanços das pesquisas no campo do melhoramento genético, expandiu-se as áreas de cultivo para regiões do Brasil Central, onde obtém-se os melhores índices de produtividade, podendo chegar até $7000 \mathrm{~kg} \cdot \mathrm{ha}^{-1}$, que está acima da média nacional de aproximadamente $2000 \mathrm{~kg} \cdot \mathrm{ha}^{-1}$ (1). As características climáticas do Centro-Oeste são favoráveis ao desenvolvimento de Brusone (Magnaporthe oryzae COUCH \& KOHN (5) patotipo Triticum (sinônimo de patotipo Pyricularia oryzae Triticum), a principal doença que afeta a cultura do trigo, nas condições ambientais de temperatura média de $27{ }^{\circ} \mathrm{C}$ e molhamento foliar superior a 10 horas, as perdas podem ser de $100 \%$.

O controle da doença com a utilização de cultivares de trigo resistentes à brusone é a melhor alternativa. Porém, existem poucas fontes de resistência genética, associada às altas proporções de mutagenicidade do fungo, que produz novas linhagens virulentas, com poucos anos de cultivo sucessivo do trigo resistente (16). Além disso, o controle químico nem sempre é eficiente, devido ao desenvolvimento da resistência do fungo aos fungicidas e a problemas durante a aplicação $(3,6)$. Portanto, o uso de alternativas como os indutores de resistência 
tem como objetivo ativar rotas metabólicas ligadas às respostas de defesa da planta ao patógeno, como por exemplo a participação de íons metálicos na formação de espécies reativas de oxigênio (EROs), que atuam na indução da defesa vegetal (10).

O zinco, além de ativar diversas enzimas na planta (síntese de clorofila e produção de auxinas), apresenta importância devido à participação na homeostase redox, que por sua vez regula a atividade da enzima NADPH oxidase, e esta influencia a produção de enzimas de defesa (18). Além disso, a disponibilidade de íons metálicos nas células das plantas, interferem na virulência e produção de toxinas do patógeno, e em sua resistência as EROs produzidas pela planta (10).

A influência do $\mathrm{Zn}$, na redução de severidade das doenças em plantas, já foi observada principalmente em doenças causadas por fungos (8). O Zn participa, em células eucarióticas, regulando diferentes caminhos para a transcrição de sinais, como a morte celular e ativação de proteínas relacionadas à patogênese, possuindo a maior família de reguladores de transcrição em plantas. Como por exemplo, tendo sua expressão em condições de estresses bióticos e abióticos em folhas e raízes de Arabidopsis thaliana (4).

A sinalização da planta aos processos invasivos do patógeno pode ocorrer por meio da produção das EROs, e a aplicação de zinco induziu a produção das mesmas nas células da planta, juntamente com a prolina (20). Esta interação promove o fortalecimento da parede celular da planta sob as hifas infectivas do fungo, na tentativa da planta em impedir o sucesso da infecção (7). Portanto, os eventos histopatológicos durante a infecção podem ser utilizados como uma ferramenta para aferição da resistência da planta à doença. $\mathrm{O}$ objetivo do trabalho foi avaliar o efeito de sulfato de zinco sobre a severidade de $M$. oryzae em folhas de trigo, a produção de íons peroxido e de morte celular pela planta.

\section{MATERIAL E MÉTODOS}

\section{Cultivo das plantas de trigo}

Foram avaliadas as cultivares de trigo Safira, Mirante, Madre pérola e Ônix, devido as suas características quanto à resistência às doenças foliares, sendo as cultivares Safira e Mirante cultivares suscetíveis, Madre Pérola moderadamente resistente, e Ônix resistente.

As cultivares foram semeadas em vasos de plástico com capacidade de $2 \mathrm{~L}$, preenchidas com $1 \mathrm{~L}$ de substrato comercial de plantas (Bio Plant Plus) e mantidas em casa de vegetação até o estádio V3, quando foi realizada a inoculação.

\section{Cultivo do isolado do fungo Magnaporthe oryzae}

O isolado monospórico de $M$. oryzae foi obtido de folhas de aveia e foi purificado e armazenado no interior de micro tubos a $-4{ }^{\circ} \mathrm{C} \mathrm{em}$ fragmentos de papel filtro. Os fragmentos colonizados foram cultivados em meio sólido de aveia ( $2 \%$ ágar $+5 \%$ flocos de aveia $+2 \%$ dextrose), a $26{ }^{\circ} \mathrm{C} \pm 2$ com fotoperíodo de 12 horas, por 15 dias, em câmara de crescimento. Após este período, cinco $\mathrm{mL}$ de solução de suspensão $(0,01 \%$ tween $+0,25 \%$ gelatina: 1 água destilada) foram vertidas em cada uma das placas colonizadas, realizou-se a raspagem superficial das colônias, obtendo-se uma suspensão $10^{4}$ conídios. $\mathrm{mL}^{-1}$.

Efeito de doses de sulfato de zinco na redução de severidade da brusone do trigo

As plantas de trigo foram cultivadas como descrito anteriormente e mantidas em casa de vegetação até o estádio V4, apenas a $3^{\mathrm{a}}$ folha recebeu aplicação de sulfato de zinco nas concentrações de 0 (água destilada); 0,$4 ; 0,8 ; 1,2$ ou $1,6 \%$. Após três dias, a mesma folha que recebeu aspersão folhar de $\mathrm{Zn}$ e aquelas aspergidas apenas com água destilada, foram inoculadas com suspensão de esporos na concentração de $10^{4}$ conídios. $\mathrm{mL}^{-1}$, utilizando aerógrafo e cilindro de $\mathrm{CO}_{2}$ com pressão de 2 atm.

Após incubação em ambiente com umidade saturada a $26{ }^{\circ} \mathrm{C} \pm 2$ por 24 horas, as plantas retornaram à casa de vegetação.

As avaliações da severidade da doença foram realizadas aos 7 dias após a inoculação. As folhas foram digitalizadas e para cada cultivar dentro de cada dose, a severidade foi quantificada com auxílio do software AFSoft 1.1 (14).

Os dados de severidade foram transformados com a equação: $\sqrt{(\mathrm{X}+0,05)}$ e submetidos à ANOVA em delineamento inteiramente casualizado, em esquema fatorial $5 \times 4$ ( 5 doses e 4 cultivares de trigo) $\mathrm{e}$ 10 repetições. Devido à interação significativa entre doses e cultivares $(\mathrm{P}=0,05)$, foram ajustadas regressões polinomiais para cada uma das cultivares. As análises foram realizadas utilizando o software SAS 9.1 (17).

\section{Efeito do sulfato de zinco sobre a infecção de trigo por Magnaporthe oryzae}

Para avaliar a influência do sulfato de zinco no processo de infecção de trigo por M. oryzae, um experimento foi conduzido em delineamento inteiramente casualizado, com aplicação foliar de sulfato de zinco a 0 e $0,4 \%$ (15), na cultivar de trigo Safira, com quatro repetições, sendo cada repetição constituída da $3^{\mathrm{a}}$ folha de uma planta de trigo.

As plantas foram mantidas em casa de vegetação, até a $3^{\mathrm{a}}$ folha totalmente expandida, a qual recebeu aplicação de sulfato de zinco a $0,4 \%$, ou água destilada. Decorridos três dias, realizou-se a inoculação de suspensão de esporos na terceira folha, na concentração de $10^{4}$ conídios. $\mathrm{mL}^{-1}$, com auxílio de aerógrafo e cilindro de $\mathrm{CO}_{2}$ com pressão de 2 atm

Após a inoculação, as plantas de trigo foram mantidas em câmara com umidade saturada a $26^{\circ} \mathrm{C} \pm 2$ por 24 horas. Decorrido esse período, as plantas foram mantidas em casa de vegetação.

As coletas das folhas foram realizadas $18,24,30,36,48$ e 72 hai e durante a coleta as mesmas foram fragmentadas transversalmente a cada centímetro, excluindo-se as extremidades.

Os fragmentos foram submersos em solução fixadora etanol+clorofórmio+ácido tricloroacético (3:1:0,15\%), por 24 horas e posteriormente armazenados em glicerol $50 \%$, ou foram imediatamente submetidos à coloração com DAB (3,3'-diaminobenzidina), para observação da produção de radicais de peróxido.

Os fragmentos armazenados em glicerol foram utilizados para a avaliação da resposta hipersensível. Os fragmentos foram corados por fervura em solução azul de trypan 0,03\% + lactofenol:etanol (1:2, v:v), durante $5 \mathrm{~min}$. Posteriormente, foram clareados em solução de cloral hidratado (5:2). A presença de morte celular do hospedeiro é indicada por células intensamente coradas com azul de trypan, que possui afinidade por células mortas e por constituintes da parede celular de fungos (12).

Para avaliar a produção de peróxido de hidrogênio, os fragmentos foram imediatamente imersos, durante a coleta, em solução de DAB $(0,1 \%)-\mathrm{HCl}(\mathrm{pH} 3,8)$, à temperatura ambiente por 30 minutos em vácuo. Após este período, os fragmentos foram mantidos em escuro durante 5 horas, transferindo-os para solução fixadora, por 24 horas, e depois imersos em cloral hidratado para clareamento.

A presença do peróxido de hidrogênio foi observada pela coloração marrom-avermelhada, formado da polimerização do peróxido de 
hidrogênio com o DAB, na presença da enzima peroxidase no momento da coleta/imersão dos fragmentos (21).

Os fragmentos coloridos com Trypan ou DAB foram montados em lâminas, com a face adaxial voltada para cima, com glicerol 50\% e selada com lamínula e esmalte.

As lâminas foram analisadas em microscópio ótico Nikon E200, com aumento de 400x. Foram avaliadas as variáveis proporção de esporos germinados, apressórios melanizados, apressórios com hifa infectiva, sítios de infecção com produção de peróxido e sítios de infecção com morte celular.

Todas as variáveis foram avaliadas nas amostras tratadas com DAB e trypan blue, com resultados semelhantes obtidos em ambas as avaliações. No entanto, foram apresentados apenas os resultados oriundos das análises obtidas nas amostras coloridas com DAB.

Os dados das proporções das variáveis avaliadas em cada um dos horários de coleta foram submetidos ao teste de $\chi^{2}(\mathrm{p}<0,05)$, em tabelas de contingência, comparando-se variáveis com e sem a aplicação do $\mathrm{ZnSO}_{4}$, para isso foram somadas as quatro repetições das amostras. As análises foram realizadas utilizando-se o software SAS 9.1 (17).

\section{RESULTADOS E DISCUSSÃO}

Efeito das doses de sulfato de zinco na redução da severidade da brusone na folha, em diferentes cultivares de trigo

As interações entre as doses de sulfato de zinco e cultivares de trigo foram significativas $(\mathrm{p}<0,05)$. A severidade da brusone, nas folhas das cultivares de trigo, reduziu com o aumento das concentrações da aplicação foliar de sulfato de zinco (Figura 1), com exceção a cultivar Ônix. A cultivar Mirante, sem aplicação foliar de sulfato de zinco, apresentou a mais elevada severidade da brusone na folha, dentre as cultivares, com $72,6 \%$.

Entretanto, com o aumento das concentrações de sulfato de zinco, houve redução da severidade, com ajuste linear (Figura 1), atingido a menor severidade em relação às cultivares Madre Pérola e Safira, com a dose de 1,6\%. De forma semelhante, a cultivar Madre Pérola, sem aplicação de sulfato de zinco apresentou a severidade de 53,5\%, também com ajuste linear e com menor severidade na maior dose de sulfato de zinco.

Por outro lado, a severidade da brusone na cultivar Safira teve ajuste quadrático (Figura 1), na dose de $0 \%$ de sulfato de zinco, a porcentagem da severidade da brusone na folha foi de $43,3 \%$, com o aumento da concentração da aplicação foliar de sulfato de zinco, a severidade da brusone reduziu para $2 \%$.

A severidade de brusone na folha da cultivar Ônix, não foi alterada em função das doses de sulfato de zinco, mantendo-se em $25 \%$ independente da aplicação. A cultivar Ônix foi previamente reportada como resistente à brusone do trigo, e possivelmente os mecanismos de resistência não estão associados à morte celular, isso porque esta cultivar apresentou o padrão de morte celular associado aos sítios de infecção semelhante à cultivar suscetível Anahuac, em resposta à infecção da folha do trigo por M. oryzae (9).

O aumento da severidade da brusone nas folhas das cultivares Mirante, Madre Pérola e Safira, na dose $0 \%$ de sulfato de zinco, pode estar associado com toxinas produzidas pelo fungo. De fato, a severidade da necrose causada pelas toxinas produzidas, durante a germinação dos esporos, é independente de sua especificidade ao hospedeiro, por outro lado, depende dos cloroplastos e fotorreceptores da planta $(11,13)$. O zinco, por sua vez, tem participação nos processos metabólicos ligados aos cloroplastos e à fotossíntese (2), dessa forma a especificidade, que leva ou não à compatibilidade entre $M$. oryzae $\mathrm{e}$ o hospedeiro, é resultado da interação em dois níveis: compatibilidade a nível de espécie, e compatibilidade a nível de raça-cultivar, sendo a suscetibilidade ou resistência determinada a nível de raça-cultivar, no estabelecimento do patógeno após a infecção, ou seja, na colonização (11).

Efeito do sulfato de zinco no processo de infecção da folha, da cultivar de trigo Safira

Para investigar quais os possíveis mecanismo histológicos envolvidos na redução da severidade, foram realizados estudos adicionais com inoculação de $M$. oryzae, e aplicação foliar de sulfato de zinco na cultivar de trigo Safira. Tendo como resultado nesta cultivar, as proporções de germinações de conídios de $M$. oryzae na folha, acima de $98 \%$ em todos os horários de avaliação (Tabela 1), com ou sem aplicação foliar de sulfato de zinco, e sem diferenças significativas ( $>>0,153)$. Somente em 72 hai houve diferença significativa entre as amostras com aplicação foliar de sulfato de zinco e sem aplicação $(p=0,010)$, quando a germinação foi de $100 \%$ sem a aplicação e de $98 \%$ com a aplicação. No entanto esta pequena diferença pode não apresentar grande impacto sobre a severidade da doença em condições de lavoura. O início da germinação dos esporos e produção de toxinas, ocorre logo após a inoculação de $M$. oryzae na planta, atingindo o ponto máximo 6 hai, com aproximadamente $80 \%$ de esporos germinados (11). De maneira

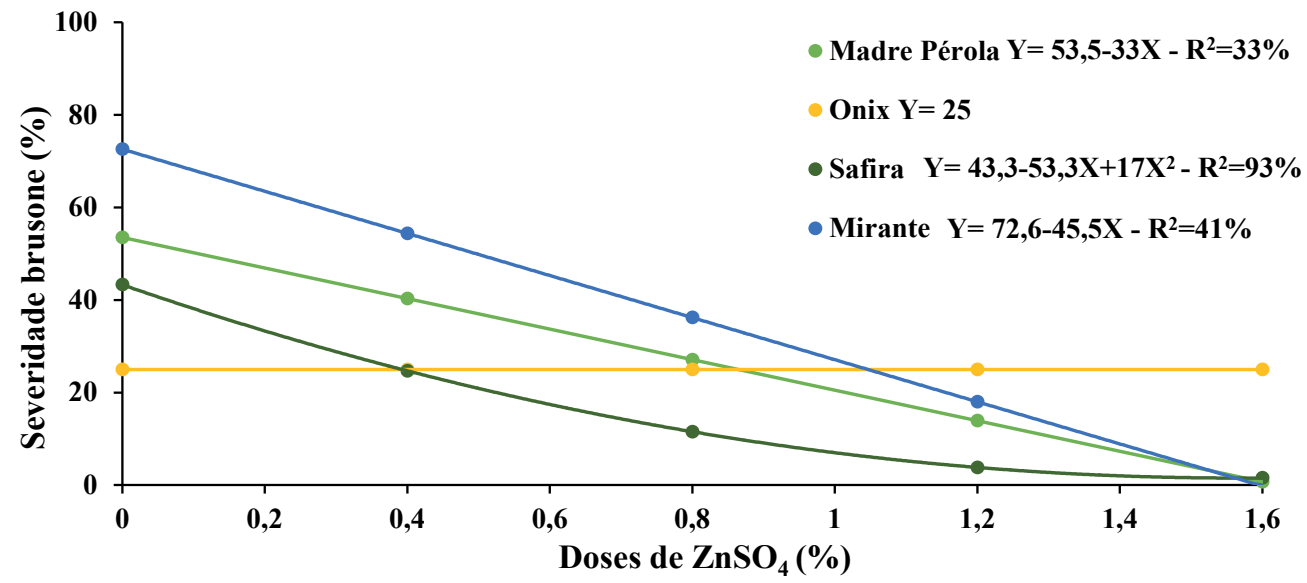

Figura 1. Severidade da brusone na folha de cultivares de trigo em função da aplicação foliar de sulfato de zinco. 
semelhante, as cultivares de trigo Ônix e BR18, que são resistentes à brusone, e Anahuac que é suscetível, com 24 hai as germinações dos esporos foram acima de $85 \%$, estabilizando as proporções de germinações nas horas seguintes (9). Similarmente, a aplicação de Si também não interferiu no desenvolvimento de $M$. oryzae em folha de trigo até 48 hai, quando houve significativa redução do desenvolvimento do fungo, em comparação as plantas sem aplicação de $\mathrm{Si}$, a redução foi ainda mais elevada com 72 hai nas plantas com aplicação de Si (19), evidenciando o efeito reduzido tanto da planta quanto dos sais sobre a fase inicial da infecção.

As proporções de apressórios melanizados de $M$. oryzae, foram acima de $95 \%$ em todos os horários de avaliação, sem diferenças significativas ( $p>0,311)$ entre amostras com ou sem aplicação foliar de sulfato de zinco (Tabela 1). Entretanto, com 36 hai nas folhas com aplicação foliar de sulfato de zinco, a proporção de apressórios melanizados do fungo sobre a folha do trigo reduziu para $94 \%$, e naquelas sem zinco aplicado e no mesmo horário após a inoculação, a proporção de germinação foi de $99 \%$, com diferença significativa $(\mathrm{p}=0,004)$.

As proporções de sítios de infecção de $M$. oryzae com hifa infectiva, na folha da cultivar de trigo Safira, com aplicação foliar de sulfato de zinco as 18 hai foi de $91 \%$, sem diferença daquelas sem aplicação foliar de zinco ( $\mathrm{p}=0,363)$. No entanto, em 36 hai a proporção de sítios com hifa infectiva, naquelas com aplicação foliar de sulfato de zinco, reduziu para $77 \%$, enquanto nas sem aplicação foliar de zinco foram de $87 \%$ ( $\mathrm{p}=0,011$ ), as diferenças foram maiores com 48 hai, quando a aplicação foliar de sulfato de zinco reduziu as proporções de hifas infectivas nos sítios de infecção para 55\%, tendo para as folhas sem aplicação foliar de sulfato de zinco $85 \%$ de hifa infectiva $(\mathrm{p}<0,001)$, porém, com 72 hai não houve diferença significativa entre os tratamentos $(p=0,297)$. Apesar das diferenças significativas, a redução da melanização de apressórios e produção de hifa infectiva, nas condições analisadas, pode não refletir em redução da severidade a campo, além disso, o método utilizado pode não ter sido eficiente em detectar estas diferenças na produção de hifas infectivas, apesar de ter avaliado mais de 150 sítios de infecção em cada horário para cada tratamento.

A proporção de produção de peróxido de hidrogênio, na folha da cultivar de trigo Safira, nos sítios de infecção por M. oryzae, com aplicação foliar de sulfato de zinco alternou entre $2 \%, 1 \%$ ou $0 \%$ após a inoculação com o fungo, sendo que a 72 hai $2 \%$ dos sítios de infecção haviam produção de peróxido de hidrogênio, com diferença significativa $(\mathrm{p}=0,045)$ das folhas sem aplicação foliar de sulfato de zinco, onde não houve produção de peróxido de hidrogênio no mesmo horário, enquanto que nas folhas sem aplicação foliar de sulfato de zinco, houve $2 \%$ de produção de peróxido de hidrogênio 18 hai, nos sítios de infecção do fungo, nos demais horários após a inoculação não mais houve produção.

A homeostase redox das células das plantas depende de íons metálicos como o zinco, esta homeostase regula a atividade da enzima NADPHoxidase que interfere na produção de peróxido de hidrogênio e na atividade de enzimas de defesa da planta, podendo participar também na composição de enzimas que fazem a conversão do peróxido de hidrogênio a moléculas não reativas (18).

A proporção de morte celular na folha da cultivar de trigo Safira, nos sítios de infecção por $M$. oryzae, com ou sem aplicação foliar de sulfato de zinco foram iguais 18 hai, com $1 \%$ de morte celular nos sítios de infecção $(p=0,748)$, no entanto, 24 hai as folhas com aplicação foliar de sulfato de zinco, haviam 13\% de morte celular nos sítios de infecção, enquanto no mesmo horário as folhas sem aplicação de sulfato de zinco, haviam 4\% de morte celular nos sítios de infecção, com diferença significativa $(\mathrm{p}=0,045)$, já com 48 hai as diferenças foram maiores, com 34\% de morte celular nos sítios de infecção, nas folhas com aplicação foliar de sulfato de zinco, enquanto naquelas sem zinco não houve morte celular, com diferença significativa $(\mathrm{p}<0,001)$, porém, com 72 hai a proporção de morte celular nos sítios de infecção por $M$. oryzae, nas folhas da cultivar de trigo Safira, com ou sem aplicação foliar de sulfato de zinco, voltam igualar-se $(p=0,087)$, sendo nas folhas com aplicação foliar haviam 4\% de morte celular nos sítios de infecção, e naquelas sem aplicação de zinco a proporção de morte celular nos sítios de infecção foi de $1 \%$. De fato, o íon de zinco é um dos fatores que regulam a morte celular, devido às respostas de defesa das células das plantas (4), portanto, a morte celular pode levar a uma amplificação de sinais de defesa e consequentemente redução dos danos causados pelo desenvolvimento do fungo no hospedeiro.

Dessa maneira, a aplicação foliar de zinco durante o ciclo da cultura pode ser realizada como medida alternativa, pelo fato de sua eficiência na redução da severidade da brusone no trigo. Entretanto, a eficiência depende de outros fatores como a dose e cultivar, o que torna imprescindível estudos com outras doses e cultivares.

\section{AGRADECIMENTOS}

Ao CNPq pela concessão de com bolsa de Mestrado (GM) ao primeiro autor.

Tabela 1. Efeito da aplicação foliar de sulfato de zinco, no processo de infecção da folha de trigo cultivar Safira, por Magnaporthe oryzae, produção de peróxido de hidrogênio e morte celular nos sítios de infecção.

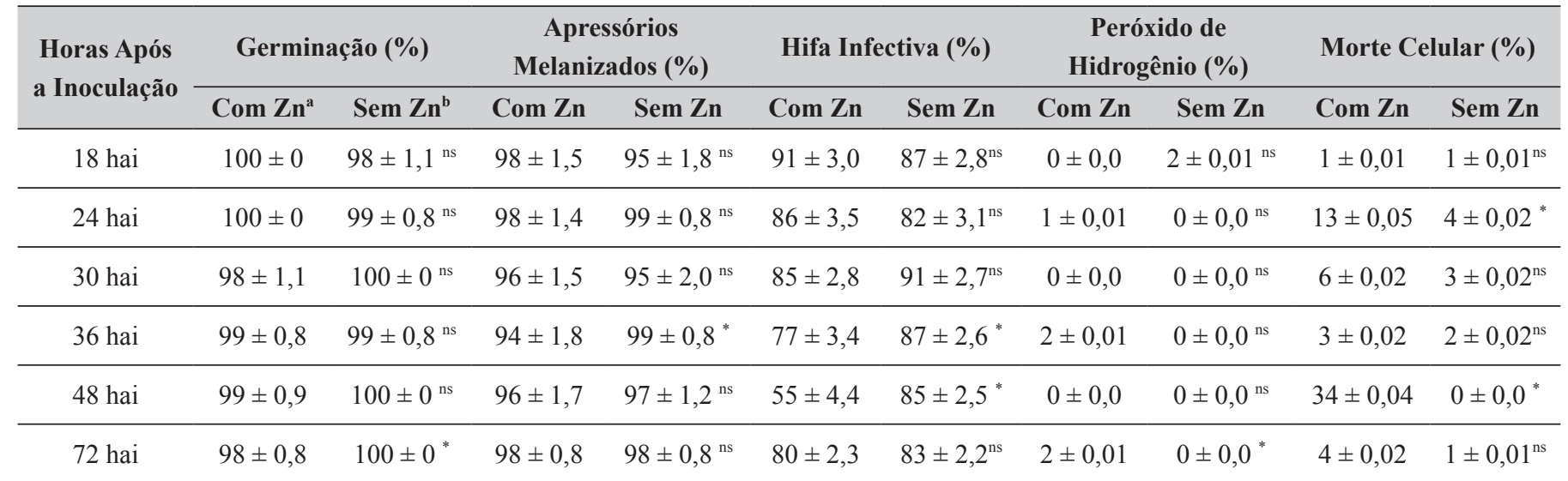

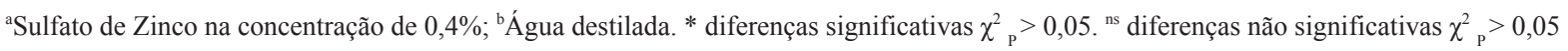




\section{REFERÊNCIAS}

1. Brasil. Companhia Nacional de Abastecimento. Perspectivas de diversificação e de investimentos na produção de arroz, trigo e feijão. Brasília, DF: Companhia Nacional de Abastecimento, 2016. 51p. (Compêndio de Estudos, 1).

2. Cakmak, I. Possible roles of zinc in protecting plant cells from damage by reactive oxygen species. Tansley Review No. 111. New Phytologist, Cambridge, v.146, n.2, p.185-205, 2000.

3. Castroagudín, V.L.; Ceresini, P.C.; De Oliveira, S.C.; Reges, J.T.A.; Maciel, J.L.N.; Bonato, A.L.V.; Dorigan, A.F.; Mcdonald, B.A. Resistance to QoI fungicides is widespread in Brazilian populations of the wheat blast pathogen Magnaporthe oryzae. Phytopathology, Saint Paul, v.105, n.3, p.284-294, 2015. DOI: http://dx.doi.org/10.1094/PHYTO-06-14-0184-R

4. Ciftci-Yilmaz, S.; Mittler, R. The zinc finger network of plants. Cellular and Molecular Life Sciences, Basileia, v.65, n.7/8, p.1150-1160, 2008. DOI: 10.1007/s00018-007-7473-4

5. Couch, B.C.; Kohn, L.M.A. Multilocus gene genealogy concordant with host preference indicates segregation of a new species, Magnaporthe oryzae, from M. grisea. Mycologia, Lancaster, v.94, n.4, p.683-693, 2002. DOI: http://www.jstor.org/stable/3761719

6. Cruz, C.D.; Santana, F.M.; Todd, T.C.; Maciel, J.L.N.; Kiyuna, J.; Baldelomar, D.F.; Cruz, A.P.; Lau, D.; Seixas, C.S.; Goulart, A.C.P.; Sussel, A.A.; Schipanski, C.A.; Chagas, D.F.; Coelho, M.; Montecelli, T.D.N.; Utiamada, C.; Custódio, A.P. Rivadeneira, M.G.; Bockus, W.W.; Valent, B. Multi-environment assessment of fungicide performance for managing wheat head blast (WHB) in Brazil and Bolivia. Tropical Plant Pathology, Lavras, v.4, n.24, p.1-9, 2018. DOI: https://doi.org/10.1007/s40858-018-0262-9

7. Deepak, S.; Shailasree, S.; Kini, R.K.; Muck, A.; Mithöfer, A.; Shetty, S.H. Hydroxyproline-rich Glycoproteins and Plant Defence. Journal of Phytopathology, Berlin, v.158, n.9, p.585-593, 2010. DOI: 10.1111/j. 1439-0434.2010.01669.x

8. Duffy, B. Zinc and plant disease. In: Datnoff, L.E.; Elmer, W.H.; Huber, D.M. Mineral Nutrition and Plant Disease. 4th ed. Saint Paul: American Phytopathological Society, 2007. p.157-179.

9. Durante, L.G.Y. Avaliação histopatológica da brusone na folha do trigo. 2014. 43p. Dissertação (Mestrado em Agronomia/Produção Vegetal) - Universidade Estadual de Mato Grosso do Sul, Aquidauana.

10. Fones, H.; Preston, G.M. The impact of transition metals on bacterial plant disease. FEMS Microbiology Reviews, Amsterdam, v.37, n.4, p.495-519,
2013. DOI: 10.1111/1574-6976.12004

11. Fujita, K.; Arase, S.; Hiratsuka, H.; Honda, Y.; Nozu, M. The Role of Toxin(s) Produced by Germinating Spores of Pyricularia oryzae in Pathogenesis. Journal of Phytopathology, Berlin, v.142, n.3, p.245-252, 1994. DOI: 10.1111/j.1439-0434.1994.tb04536.x

12. Graichen, F.A.S.; Martinelli, J.A.; Wesp, C.L.; Federizzi, L.C.; Chaves, M.S. Epidemiological and histological components of crown rust resistance in oat genotypes. European Journal of Plant Pathology, Dordrecht, v.131, n.3, p.497-510, 2011. DOI: 10.1007/s10658-011-9825-z

13. Iedome, M.; Arase, S.; Honda, Y.; Nozu, M. Light-Dependent Necrosis Formation by Magnaporthe grisea Toxin(s) in Rice cv. Sekiguchi-asahi. Journal of Phytopathology, Berlin, v.143, n.6, p.325-328, 1995. DOI: 10.1111/j.1439-0434.1995.tb00269.x

14. Jorge, L.A.C.; Silva, D.J.C.B. AFSoft. Software para a análise foliar. Versão 1.1. Embrapa. Instrumentação Agropecuária.

15. Ma, D.; Sun, D.; Wang, C.; Ding, H.; Qin, H., Hou, J.; Huang, X.; Xie, Y.; Guo, T. Physiological Responses and Yield of Wheat Plants in Zinc-Mediated Alleviation of Drought Stress. Frontiers in Plant Science, Lausanne, v.8, n.860, p.1-12, 2017. DOI:10.3389/fpls.2017.00860

16. Peng, Z.; Garcia, E. O.; Lin, G.; Hu, Y.; Dalby, M.; Migeon, P.; Tang, H.; Farman, M.; Cook, D.; White, F.F.; Valent, B.; Liu, S. Effector Gene Reshuffling Involves Dispensable Mini-chromosomes in the Wheat Blast Fungus. bioRxiv, New York, v.15, n.9, p.e1008272, 2018. DOI: https:// doi.org/10.1101/359455

17. SAS Institute Inc. 2015. SAS/IML® 14.1 User's Guide. Cary, NC: SAS Institute Inc.

18. Segal, L.M.; Wilson, R.A. Reactive oxygen species metabolism and plant-fungal interactions. Fungal Genetics and Biology, Orlando, v.110, n.1, p.1-9, 2018. DOI: https://doi.org/10.1016/j.fgb.2017.12.003

19. Sousa, R.S.; Rodrigues, F.Á.; Schurt, D.A.; Souza, N.F.A.; Cruz, M.F.A. Cytological aspects of the infection process of Pyricularia oryzae on leaves of wheat plants supplied with silicon. Tropical Plant Pathology, Lavras, v.38, n.6, p.472-477, 2013. DOI: 10.1590/s1982-56762013000600002

20. Tripathi, B.N.; Gaur, J.P. Relationship between copper- and zinc-induced oxidative stress and proline accumulation in Scenedesmus sp. Planta, Berlin, v.219, n.3, p.397-404, 2004.

21. Wesp-Guterres, C.; Martinelli, J.A.; Graichen, F.A.S.; Chaves, M.S. Histopathology of durable adult plant resistance to leaf rust in the Brazilian wheat variety Toropi. European Journal of Plant Pathology, Dordrecht, v.137, n.1, p.181-196, 2013. DOI: 10.1007/s10658-013-0232-5 